\section{Magnesium isotopes as a paleo-proxy for enhanced crustal reworking during the Precambrian-Cambrian transition - a case study from lowermost Cambrian sedimentary rocks from Koksu, Kazakhstan}

\author{
JESSICA A STAMMEIER ${ }^{1}$, DORTHEE HIPPLER ${ }^{2}$, \\ MARTIN DIETZEL ${ }^{2}$, OLIVER NEBEL ${ }^{3}$, ALBRECHT LEIS ${ }^{4}$, \\ CYRILL GRENGG $^{2}$, FLORIAN MITTERMAYR ${ }^{2}$ AND \\ SIMONE A. KASEMANN ${ }^{5}$
}

${ }^{1}$ GFZ Potsdam

${ }^{2}$ Graz University of Technology

${ }^{3}$ Monash University

${ }^{4} \mathrm{Jr}$ AquaConSol

${ }^{5}$ MARUM - Center for Marine Environmental Sciences

Presenting Author: jessica.stammeier@gfz-potsdam.de

The Precambrian-Cambrian (Pc-C) boundary has long been recognized as one of the most fascinating time intervals of Earth's history. This transition from the Proterozoic to the Phanerozoic Eon was accompanied by the rise of metazoan life, a key and unique milestone in the bio-geochemical evolution. Concomitant continental re-organization and collision were associated with enhanced continental reworking and changes in global ocean currents, with profound impacts on continental weathering rates, riverine run-off and associated changes in the ocean nutrient budget. The causal relationship between the geological re-organisation of continents and the biologic evolution of marine life, however, remains elusive. A key deposit for this time period is the phosphatic sedimentary succession from the earliest Cambrian at the Koksu section in Kazakhstan. Based on geochemical and petrographic investigations we consider this succession representative for contemporaneous ocean chemistry. In this study, we investigate the application of $\mathrm{Mg}$ isotopes as a paleo-proxy in this sedimentary succession from a shallow-water environment. We show that the temporal response in ocean chemistry consequent to crustal reworking is remarkably fast. A rapid change (over ca. 3 Myrs) towards heavier stable $\mathrm{Mg}$ isotope compositions co-varies with changes in radiogenic $\mathrm{Sr}$ isotope signatures. We propose that ocean chemistry at the Pc-C boundary, represented through this covariation, was strongly affected by continental re-organization and associated weathering, which, in analogy, would have affected ocean nutrient levels. A rapid reversal of isotope compositions towards signatures similar to those prior to the isotope excursion likely reflects the fading influence of weathering and a buffering of water-rock interactions during oceanic spreading. We conclude that, based on the positive, coupled ${ }^{87} \mathrm{Sr} /{ }^{86} \mathrm{Sr}-\delta^{26} \mathrm{Mg}$ isotope spike in ocean water chemistry, a link between Gondwana re-organization at the Pc-C boundary and the marked change in marine fauna seems plausible, rendering $\mathrm{Mg}$ isotopes a valuable paleo-proxy.

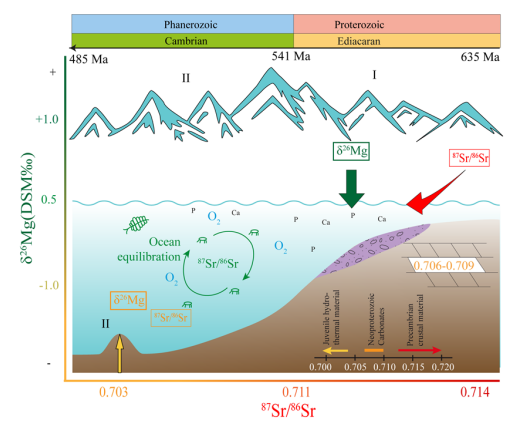

